\title{
VIRUS DE L'HÉPATITE B ET HÉPATOCARCINOME
}

\section{Pierre Tiollais Anne Dejean Marie-Annick Buendia}

\section{RÉFÉRENCES}

1. Tiollais P, Pourcel C, Dejean A. The hepatitis B virus. Nature 1985 ; 317 : 489-95.

2. Ganem D, Varmus HE. The molecular biology of hepatitis B viruses. Ann Rev Biochem $1987 ; 56: 651-94$.

3. Sureau C, Romet-Lemonne JL, Mullins JI, Essex M. Production of hepatitis B virus by a differentiated human hepatoma cell line after transfection with clones circular HBV DNA. Cell 1986; $47: 37-47$.

4. Pourcel C. Souris transgéniques pour le génome du virus de l'hépatite $\mathrm{B}$. médecine/s. ciences $1989 ; 5$ : 626-36.

5. Bartenschlager $\mathrm{R}$, Schaller $\mathrm{H}$. The aminoterminal domain of the hepadnaviral P-gene encodes the terminal protein (genome-linked protein) believed to prime reverse transcription. $E M B O$ J 1988 ; 7 : 4185-92.

6. Chang LJ, Pryciak P, Ganem D, Varmus HE. Biosynthesis of the reverse transcriptase of hepatitis $\mathrm{B}$ viruses involves de novo translational initiation not ribosomal frameshifting. Nature $1989 ; 337: 364-8$.

\section{ADRESSE}

P. Tiollais : professeur à l'Université Paris $V$, professeur à l'Institut Pasteur. A. Dejean : chargée de recherche à l'Inserm. M.A. Buendia : directeur de recherche au Cnis. Unité de Recombinaison et Expression génétique, Inserm U. 163, Cnrs URA 271, Institut Pasteur, 28, rue du Docteur-Roux, 75724 Paris Cedex 15, France.

TIRÉS A PART

\section{P. Tiollais.}

es hépatites sont des maladies connues depuis l'antiquité, mais c'est seulement au début du siècle que l'origine virale de certaines d'entre elles a été établie. Quatre virus appartenant à des familles différentes sont impliqués dans les hépatites virales chez l'homme. Bien que les symptomatologies de ces hépatites soient très voisines, les structures et les modes de réplication de ces virus sont entièrement différents. L'hépatite $\mathrm{A}$ est due à un picornavirus, l'hépatite $\mathrm{B}$ à un virus hépadna, et l'hépatite non- $\mathrm{A}$ non- $\mathrm{B}$, transmise par voie parentérale et récemment appelée hépatite $\mathrm{C}$, à un flavivirus. De plus, l'agent delta qui surinfecte les malades atteints d'hépatite $B$ est un viroïde. La guérison de l'hépatite $B$ est très fréquente chez l'adulte mais les formes chroniques ne sont pas exceptionnelles. Le tableau clinique en est très variable : porteurs sains, hépatites chroniques, cirrhoses. Enfin, et c'est là un point crucial, le VHB peut être à l'origine du cancer du foie ou hépatocarcinome. Depuis la découverte de l'antigène de surface du virus de l'hépatite $B$ (VHB, ou HBV en anglais) par B. Blumberg en 1963, l'étude de la biologie moléculaire du VHB [1, 2] a été longtemps très handicapée par l'absence de système de culture cellulaire capable de propager le virus.

En 1978-1979, la technologie de l'ADN recombinant a été appliquée au VHB. Le génome a été cloné et séquencé, ce qui a permis d'étudier l'expression génétique du virus et de développer des vaccins recombinants. Au même moment la découverte de modèles animaux porteurs de virus très comparables au VHB et appelés les virus hépadna, a permis de compléter de façon très efficace les études de biologie moléculaire sur cette famille de virus. Enfin l'obtention récente de systèmes de culture cellulaire [3] et de souris transgéniques pour le génome du VHB [4] a permis de créer d'autres modèles expérimentaux très prometteurs.

Le VHB est constitué d'une nucléocapside emballée dans une enveloppe. Le génome viral a une structure très particulière, qui a déjà été décrite dans ces colonnes $\left(\mathrm{m} / \mathrm{s} n^{\circ} 4\right.$, vol. 4, p. 249 et [4]) et est rappelée dans l'article de D. Kremsdorf et al. (p. 108 de ce numéro).

Des virus analogues du VHB ont été isolés chez la marmotte, le canard de Pékin et l'écureuil formant avec le VHB le groupe des virus hépadna. Leurs organisations génétiques sont très analogues à celle du VHB. C'est chez le virus du canard de Pékin que le mode de réplication des hépadnavirus a été établi initialement, mécanisme confirmé ensuite chez les autres virus hépadna et qui n'est pas sans rappeler celui des rétrovirus [4]. Une autre analogie est que rétrovirus et hépadna infectent les cellules sans les détruire, ont des gènes qui sont portés par le même brin, dans une configuration analogue, et sont oncogènes.

Les études épidémiologiques ont montré qu'il existe une très forte corrélation entre la prévalence de l'infection chronique par le VHB et l'incidence d'hépatomes; cette infection constitue même le seul facteur de risque tumorigène retrouvé. Cette corrélation est confirmée par les observations chez les animaux. Les marmottes infectées par le virus de l'hépatite de la marmotte (WHV) développent un hépatome dans les deux années qui suivent l'infection dans une proportion de plus de $80 \%$. De même, environ $50 \%$ des écureuils infectés par le virus de l'hépatite de l'écureuil (GSHV) présentent une tumeur hépatique dans un délai un peu supérieur, quatre à six années. Chez l'homme la période de latence qui précède l'apparition du cancer hépatique est plus longue (20 années ou plus) et les tumeurs se développent le plus souvent sur cirrhose hépatique.

Le rôle du VHB sur le développement de l'hépatome est-il direct ou indirect 
par l'intermédiaire d'une cirrhose? Cette question reste posée. Contrairement à de nombreux virus oncogènes, le VHB ne porte pas de gène transformant, et est d'ailleurs incapable de transformer des cellules en culture. De plus, la longue période de latence qui précède le développement de la tumeur n'est pas en faveur d'une intervention directe d'un oncogène. Une autre hypothèse consiste en un dérèglement de l'expression d'un oncogène à la suite de l'insertion du génome du VHB à proximité. Ce mécanisme est connu pour les rétrovirus qui induisent lentement des carcinomes et des leucémies chez les mammifères et les oiseaux. Dans les hépatomes humains, on trouve fréquemment des séquences de VHB intégrées dans l'ADN cellulaire, non seulement dans des tumeurs positives pour l'antigène $\mathrm{HBs}$, mais aussi dans des tumeurs négatives pour cet antigène et même parfois dans le foie de sujets atteints d'hépatite chronique: cela suggère que l'intégration peut être un événement très précoce dans la tumorigenèse. Une telle intégration semble d'autant plus importante dans les mécanismes d'oncogenèse qu'elle n'est nullement obligatoire pour la réplication virale. L'analyse des séquences virales intégrées a fourni des informations sur la structure de ces séquences. L'insertion virale a souvent lieu au niveau de la région cohésive du génome viral au voisinage des extrémités 5' des deux brins du génome. Elle prend place dans différents chromosomes et s'accompagne souvent de réarrangements chromosomiques, délétions, translocations dont les conséquences sont encore mal connues. Dans un hépatome humain précoce [7], nous avons récemment montré l'insertion d'un fragment d'ADN unique dans un gène codant pour un membre de la famille des récepteurs des hormones thyroïdiennes et stéroïdes. Cette observation nous a permis d'isoler ce gène et de l'identifier comme le gène du récepteur de l'acide rétinoïque. L'insertion virale s'était effectuée dans un exon du gène avec conservation de la phase de lecture. Le gène récepteur de l'acide rétinoïque se trouvait placé sous le contrôle d'un promoteur viral. L'acide rétinoïque exerce un effet sur la différenciation cellulaire au cours de l'embryogenèse en contrôlant l'expression génétique par interaction avec des récepteurs nucléaires. Il est ainsi concevable que la mutagenèse du gène du récepteur de l'acide rétinoïque par insertion de l'HBV ait joué un rôle dans la carcinogenèse hépatique. Dans un autre cas, présentant des caractères histopathologiques analogues (nodule précoce sans cirrhose) l'ADN du VHB a été trouvé intégré dans le gène de la cycline $\mathrm{A}$, une protéine exerçant un rôle régulateur sur le cycle cellulaire [8].

D'autres résultats en faveur du rôle de l'intégration des virus hépadna ont été obtenus dans notre laboratoire au cours de l'étude d'hépatomes induits par infection naturelle de la marmotte par le WHV. Comme chez l'homme, on observe dans ces hépatomes des séquences virales intégrées. Dans environ $30 \%$ des cas étudiés, nous avons observé une intégration du WHV à proximité des oncogènes $c-m y c$ [9] et $N$-myc. Les gènes $m y c$ sont impliqués dans le contrôle de la croissance et la différenciation cellulaire. L'activation des gènes $m y c$ de la marmotte est comparable à celle obtenue par les rétrovirus dans les tumeurs lymphoïdes de la souris. La synthèse des protéines myc stimulée par l'insertion virale échappe alors au contrôle cellulaire, ce qui entraîne une dérégulation de la croissance cellulaire. Jusqu'à maintenant de telles observations n'ont pas été rapportées chez l'homme. Il est possible que d'autres oncogènes soient des cibles d'insertion de l'HBV, comme le suggèrent les deux cas de mutagénèse insertionnelle observés chez l'homme. Pourtant, dans de nombreux cas, un rôle direct du virus dans le développement de l'hépatome n'a pas pu être mis en évidence et des mécanismes différents ont été proposés, dans lesquels l'intervention virale est plus indirecte. Dans un modèle de souris transgéniques qui surexprime la grande protéine d'enveloppe du VHB, on observe une nécrose hépatique suivie d'une régénération cellulaire qui conduit inexorablement à l'hépatome [10]. Matsubara et al. ont montré chez l'homme l'activation d'un oncogène appelé Ica, un nouveau gène impliqué seulement dans les hépa- tomes [11]. Le mécanisme de transformation attribué à cet oncogène n'est probablement pas lié à l'infection virale. D'autres altérations génétiques ont également été observées dans les hépatomes humains, comme la délétion de régions chromosomiques portant de probables anti-oncogènes sur les chromosomes $4 \mathrm{q}, 1 \mathrm{lp}$, $13 q$ ou $17 p$, ou l'amplification du chromosome $8 \mathrm{q}$ au locus c-myc. De tels accidents génétiques sont fréquents dans différents types de cancers humains, sans infection virale apparente. L'ensemble des travaux rapportés a apporté des arguments, d'une part en faveur d'un rôle direct de l'intégration virale, et d'autre part en faveur d'un rôle indirect du virus par l'intermédiaire d'une régénération hépatique et d'une cirrhose. Des études complémentaires sont encore nécessaires pour comprendre précisément le rôle du VHB à l'échelon moléculaire

\section{RÉFÉRENCES}

7. Dejean A, Bougueleret L, Grzeschick KH, Tiollais P. Hepatitis B virus DNA integration in a sequence homologous to $\mathrm{v}$-erb- $\mathrm{A}$ and steroid receptor genes in a hepatocellular carcinoma. Nature $1986 ; 322$ : 70-2.

8. Wang J, Chenivesse X, Henglein B, Bréchot C. Hepatitis B virus integrates within a cyclin A gene in a human hepatocellular carcinoma. Nature $1990 ; 343$ : 557-7.

9. Hsu TY, Möröy T, Etiemble J, et al. Activation of $\mathrm{c}-\mathrm{myc}$ by woodchuck hepatitis virus insertion in hepatocellular carcinoma. Cell 1988 ; 55 : 627-35.

10. Chisari FV, Klopchin K, Moriyama T, et al. Molecular pathogenesis of hepatocellular carcinoma in hepatitis B virus transgenic mice. Cell $1989 ; 59$ : 1145-56.

11. Ochiya T, Fujiyama A, Fukushige S, Hatada I, Matsubara K. Molecular cloning of an oncogene from a human hepatocellular carcinoma. Proc Natl Acad Sci USA 1986 ; 83 : 4993-7. 